I am inclined to doubt the wisdom of trusting to an airbubble for the thorough mixing of the contents of a long, narrow syringe. In such bubbles move very slowly and grudgingly. Why not pass a teaspoon through the flame of a spirit lamp and discharge and refill the syringe into and from it several times? I am, Sir, yours faithfully,

Coventry, Oct. 16th, 1916.

A. F. BILL.

\section{THE AGGLUTINATION OF MENINGOCOCCI IN RELATION TO CURATIVE SERUMS.}

\section{To the Editor of THE LANCET.}

SIR,- - The treatment of epidemic cerebro-spinal meningitis by intrathecal injections of immune serum has given somewhat uncertain results during the past two years in Great Britain. On this account the findings of an investigation into the agglutinative properties of divers serums, despite the fact that these serums were only tested against two strains of meningococci, may be of interest to those concerned with the treatment of this disease.

Since the microscopic test in the case of non-motile organisms allows at least the possibility of leaving something to imagination, I made use of Dreyer's macroscopic method of testing for agglutination. In this method positive reactions are marked by a definite flocculent depo-it and by a clearing up of the supernatant fluid. As a control the homologous serum for each strain of meningococci was used. In addition to this a normal serum and also the serum of a man who had recovered from the disease 12 months previously were employed.

From the spinal fluid of two patients, Q. and W., under the care of Deputy Surgeon-General Robert Hill, C.V.O., at the Royal Marine Infirmary, Deal, pure cultures of a Gram-negative diplococcus, growing at $37^{\circ} \mathrm{C}$., but not at $22^{\circ} \mathrm{C}$., and fermenting glucose-litmus-peptone-ascitic water, but not saccharose litmus-peptone-ascitic water-the diplococcus meningitidis-were isolated. Incidentally these cultures retained their characteristics through many subcultures. In testing the agglutinating properties of the serums on these two strains of meningococci an emulsion of a 16-hours growth was employed. The serums tested were diluted 1 in 10,1 in 15, 1 in 25,1 in 50, 1 in 125, and 1 in 250 .

Meningococci from the patients $Q$. and $W$. were not agglutinated by normal serum, by serum from a patient who had recovered 12 months ago, by the antimeningococcus serum of the Wellcome Physiological Research Laboratories (A. 1289 $D$.), or by the following antimeningococcus serums from the Pasteur Institute of Paris-(3636) Gordon strain 1, (3639) Gordon strains 2 and 3 , and (3635) monovalent, all prepared in February, 1916 -in any of the above dilutions.

The meningococci from the patient $Q$, were not agglutinated by serum from the patient $W$. in any of the above dilutions. They were agglutinated by their homologous serum from patient $Q$. and also by the polyvalent serum of the Pasteur Institute (January, 1916) in dilutions of 1 in 10 , 1 in 15 , and 1 in 25 . Lastly, this strain of meningococci was agglutinated by the antimeningitis serum of the Rockefeller Institute, New York (17/11/15) in dilutions from 1 in 10 to 1 in 125.

Meningococci from the patient $W$. were not agglutinated by serum from the patient $Q$. or by the polyvalent serum of the Pasteur Institute in any of the foregoing dilutions. They were agglutinated by their own homologous serum from the patient $W$. in dilutions from 1 in 10,1 in 15 , and 1 in 25 , and they were agglutinated by the serum of the Rockefeller Institute in dilutions from 1 in 10 to 1 in 250 .

This investigation was repeated on three occasions, and the results remained constant. The value of the serum prepared at the Rockefeller Institute, New York, as judged by the agglutination of these two strains of meningococci, is very apparent, and it may be suggested that early lumbal puncture, followed by intrathecal injection of this serum should lead to results as brilliant as those originally achieved by Flexner.

Of the two cases to which reference has been made, both fulminant in type at the onset, one (W.) has made a complete recovery. This patient had an intrathecal injection of Flexner's serum (40 c c.) six hours after the onset of the disease. The other patient (Q.) died after three months' illness. He received an early intrathecal injection of one of other serums enumerated, but did not have Flexner's serum (40 c.c.) until the eighth day of his illness. I am, Sir, yours faithfully,

Harley-street, W., Oct. 10th, 1916. HALLIDAY SUTHERLAND.

\section{"CLERGYMEN'S SORE-THROAT."}

To the Editor of THE LANCET.

SIR,-It is now over 30 years since I first asked myself why we speak of chronic pharyngitis and laryngitis produced by over-speaking, as " clergymen's sore-throat" and not as barristers' sore-throat. Why is this condition so rarely seen in barristers who use their voices more than clergymen, and in stuffier atmospheres? On thinking over the matter the only difference I could perceive between a clergyman's and a barrister's speaking was that a clergyman spoke down to his congregation, and a barrister spoke $u p$ to the judge, the former thus pressing on his larynx and causing congestion thereof, whereas the barrister had his larynx and throat in a normal position, or rather in a hypernormal position. From that time I have always advised such cases to speak looking $u p$ to their audience and never down. I have used no local applications or treatment except to rectify a condition such as granular pharyngitis, but where necessary have suggested a rest of voice for two or three months.

In all cases this plan has been successful. I will only quote one case, an American lady with complete loss of her speaking voice; she was a public lecturer and had had to relinquish her calling, no treatment having benefited her. After three months' rest of voice she resumed her occupation, now 12 years ago, and has never since had loss of voice. During this period she had made no alteration in her manner of public speaking, except that she has declined to use any buildings which involved speaking down to her audience, and has therefore always spoken looking $u p$ from the well of a theatre.

I was much interested a few years ago to see Professor Keith's statement that the human voice would never have become developed had we not first attained the upright posture, which, it seems to me, bears out the raison diêtre of the treatment mentioned above.

I am, Sir, yours faithfully,

Weymouth-street, W., Oct. 17th, 1916. GEO. STEELE-PERKINS

\section{THE ROYAL ARMY MEDICAL CORPS GAZETTES.}

To the Editor of THE LANCET.

SIR,--The Royal Society of Medicine has received from time to time a few odd numbers of these Gazettes, probably sent to us by Fellows at the front, and I would like with your kind permission to invite those responsible for the publication of these Gazettes that they would endeavour to send to us complete sets, which would be bound and carefully preserved in our library. I need scarcely enlarge on the interest that will attach to such a collection in the years to come, and as, under the conditions that prevail at the front, it is not likely that many complete sets will be preserved, they are sure to become exceedingly scarce and probably unobtainable after the war.

I should be very grateful to any who, seeing this letter, will help me in trying to preserve a complete set of all the Gazettes in this library. I am, Sir, yours faithfully, J. Y. W. M ACALISTER.

Royal Society of Medicine, 1, Wimpole-street, W. Oct. 14th, 1916.

Medical Society of London.-An incident of historical interest is the removal of the fine terra-cotta plaque which was presented by the founder of this society, Dr. John Coakley Lettsom, in 1778, from the original meeting house, No. 3, Bolt-court, Fleet-street, and its installation in the present home in Chandos-street, Cavendish-square. The central figure of the plaque represents the Isis of Sais, the fabled revealer of the mysteries of Nature and the presiding genius of medicine. It is flanked on either side by a sphinx symbolising mystery, while a serpent, emblematic of eternity, bears the inscription, in Greek, "I am whatever is or has been or will be, and no mortal has hitherto drawn aside my veil." 